\title{
RUANG KOLEKTIF DI WIJAYA KUSUMA
}

\author{
Vensiscaria $^{1)}$, Mieke Choandi²) \\ 1) Program Studi S1 Arsitektur, Fakultas Teknik, Universitas Tarumanagara, vensiscariathenardo@gmail.com \\ 2) Program Studi S1 Arsitektur, Fakultas Teknik, Universitas Tarumanagara, mieke@untar.ac.id
}

\begin{abstract}
Abstrak
Faktanya masyarakat Jakarta rata-rata memiliki kegiatan yang hanya berkisar di ruang lingkup first place (rumah-tempat tinggal) dan second place (kantor-tempat bekerjatempat belajar), hal ini terus menerus berulang hingga menjadi sebuah rutinitas yang membosankan. Oleh karena itu mereka butuh suatu tempat in between dari rutinitas ruang lingkup mereka sehari hari. Namun ironisnya ketika masyarakat membutuhkan ruang publik untuk dapat berinteraksi dengan sesamanya, tidak ditemukan tempat di luar lingkungan first place dan second place untuk melakukan kegiatan ataupun sekedar berkumpul antar sesama dikarenakannya minimnya atau bahkan tidak adanya fasilitas ruang publik untuk mewadahi mereka yang didasari oleh keterbatasan ruang. Oleh karena itu, masyarakat membutuhkan sebuah wadah Third place yang dapat menjadi tempat untuk jawaban atas kebutuhan ruang yang mereka butuhkan. Bukan hanya sebagai tempat melepaskannya stress dan kejenuhan akibat rutinitas, tapi juga sebagai wadah untuk bersosialisasi dengan saudara, teman-teman maupun tetangga yang berasal dari latar belakang berbeda agar dapat hidup saling respek dan berdampingan, yang dimana nantinya kesenjangan sosial tidak terekspos sama sekali guna membentuk sifat humanis, terbuka, dinamis, dan produktif bagi tiap individu. Hal-hal tersebut yang membuat kebutuhan akan Third place untuk menjembatani kehidupan dalam rumah dan aktifitas kerja dengan kegiatan informal sangat dibutuhkan.
\end{abstract}

\section{Kata kunci: arsitektur; Jakarta; third place}

\begin{abstract}
The fact is that the average Jakarta community has activities that only revolve around the scope of the first place (home-place of residence) and second place (office-place of workplace of study), this continues over and over until it becomes a boring routine. Therefore they need somewhere in between of their daily scope of routine. But ironically, when people need public space to be able to interact with each other, there is no place outside the first place and second place to do activities or just gather among people because of the lack or even the absence of public space facilities to accommodate them based on space limitations. Therefore, people need a Third place container that can be a place for answers to the needs of the space they need. Not only as a place to release stress and boredom due to routine, but also as a place to socialize with relatives, friends and neighbors who come from different backgrounds so they can live in mutual respect and side by side, where social inequalities will not be exposed at all to form humanistic, open, dynamic, and productive for each individual. These things that make the need for Third place to bridge life in the home and work activities with informal activities are needed.
\end{abstract}

Keywords: architecture; Jakarta; third place

\section{PENDAHULUAN}

DKI Jakarta sebagai kota metropolitan sekaligus ibu kota negara Indonesia merupakan kota yang sangat sibuk dan memiliki segudang masalah yang kompleks. Kota yang terdiri dari 6 kabupaten (Jakarta Utara, Jakarta Timur, Jakarta Pusat, Jakarta Selatan, Jakarta Barat, dan Kepulauan Seribu) ini memiliki tingkat kepadatan yang tinggi dimana sangat berbanding terbalik 
dengan tingkat ruang terbuka hijau / ruang publik yang sangat rendah. Hal ini merupakan akibat dari banyaknya jumlah penduduk yang membutuhkan tempat untuk tinggal dan bekerja, sehingga ruang ruang publik yang ada pun beralih fungsi.

Faktanya hubungan sosial di Jakarta yang dipengaruhi oleh faktor eksternal kian hari pun semakin renggang yang mengakibatkan seseorang menjadi individualis. Hal ini juga diungkapkan oleh Gendhotwukir (2016), peneliti dari Merapi Cultural Institute. la mengatakan bahwa, "Revolusi industri, transportasi, teknologi, dan pasar berangsur-angsur mengubah kondisi kehidupan sosial. Ideologi individualisme muncul karena arogansi kaum industrialis yang memunculkan praktik perbudakan sehingga menciptakan strata kelas". Menurutnya, manusia hidup terkotak-kotak dalam kubikel, spesialisasi, partisi, apartemen, dan cluster yang membuat penghuninya berjarak dengan sekitarnya. Sebagian besar mereka sedang mengalami krisis toleransi antar sesama individu, kurangnya sikap humanis, cenderung tertutup, tidak dinamis dan tidak produktif, yang tercermin dimana antar masyarakat tidak saling mengenal, meskipun dalam satu lingkungan. Lingkungan pemukiman yang terbentuk terasa sangat membosankan dan mengisolasi masyarakat, ditambah dengan lingkungan pekerjaan yang cenderung memberikan stress.

Faktanya masyarakat Jakarta merupakan masyarakat yang anggotanya terdiri dari bermacam macam lapisan atau tingkatan hidup yang berbeda latar belakang, pendidikan, kebudayaan, dan sebagainya. Mereka rata-rata memiliki kegiatan yang hanya berkisar di ruang lingkup first place (rumah-tempat tinggal) dan second place (kantor-tempat bekerja-tempat belajar), hal ini terus menerus berulang hingga menjadi sebuah rutinitas yang membosankan. Oleh karena itu mereka membutuhkan suatu tempat in between dari rutinitas ruang lingkup mereka sehari hari. Namun ironisnya ketika masyarakat membutuhkan ruang publik untuk dapat berinteraksi dengan sesamanya, tidak ditemukan tempat di luar lingkungan first place dan second place untuk melakukan kegiatan ataupun sekedar berkumpul antar sesama dikarenakannya minimnya atau bahkan tidak adanya fasilitas ruang publik untuk mewadahi mereka yang didasari oleh keterbatasan ruang.

Oleh karena itu, masyarakat membutuhkan sebuah wadah third place yang dapat menjadi tempat untuk jawaban atas kebutuhan ruang yang mereka butuhkan. Bukan hanya sebagai tempat melepaskannya stress dan kejenuhan akibat rutinitas, tapi juga sebagai wadah untuk bersosialisasi dengan saudara, teman-teman maupun tetangga yang berasal dari latar belakang berbeda agar dapat hidup saling respek dan berdampingan, yang dimana nantinya kesenjangan sosial tidak terekspos sama sekali guna membentuk sifat humanis, terbuka, dinamis, dan produktif bagi tiap individu. Hal-hal tersebut yang membuat kebutuhan akan third place untuk menjembatani kehidupan dalam rumah dan aktifitas kerja dengan kegiatan informal sangat dibutuhkan.

\section{KAJIAN LITERATUR \\ Third place}

Berdasarkan buku yang berjudul The Great Good Place, Oldenburg (1999), terdapat tiga kategori tempat yang secara umum masyarakat alami, yakni first place, second place, dan third place. First place merupakan hunian-tempat tinggal yang dimana interaksi sosial didalamnya bersifat pengalaman pribadi, terstruktur, berhirarki, terkontrol, dan pengekspresian diri umumnya terbatas. Di sisi lain, second place adalah tempat kedua dimana seseorang menghabiskan waktu, bisa merupakan tempat kerja maupun tempat belajar yang dimana interaksi sosial didalamnya bersifat terstruktur dan terorganisir, bersuasana formal, memberikan pengalaman sosial.

Sedangkan third place merupakan tempat yang mewadahi kebutuhan masyarakat yang mencakup tempat untuk memikirkan tujuan hidup, waktu untuk menyendiri, maupun bertukar pikiran membicarakan berbagai hal diluar kesibukan rutinitasnya di rumah (yang merupakan first place) maupun tempat kerjanya (yang merupakan second place). Third place adalah tempat publik yang netral, sebagai tempat alternatif, siapapun dapat kesana, dapat digunakan untuk 
berbagai aktivitas oleh berbagai kalangan. Third place ada dimana mana dan memiliki bentuk yang beragam sesuai dengan kehidupan dan budaya masyarakatnya. Istilah third place tidak hanya mengarah kepada tempat-tempat hangout seperti kafe dan bar, tetapi juga mengarah pada ruang-ruang terbuka kota, seperti taman kota, plaza, dan sidewalk dimana masyarakat dapat menghabiskan waktu untuk berkumpul dengan saudara atau teman-teman sambil menikmati suasana kota. Oleh karena itu third place juga disebut sebagai a public meeting place (Larice dan Macdonad, 2007).

Berdasarkan buku yang berjudul The Great Good Place, Oldenburg (1999), terdapat 8 karakteristik third place, yakni :

- Neutral ground: tidak terikat dari segi politik, ekonomi, aspek lainnya, pengunjung tidak memiliki obligasi dan bebas untuk mendatangi tempat tersebut.

- Leveler: tidak memandang status, third place menerima semua kalangan tanpa syarat partisipasi.

- Dialogical: komunikasi sebagai kegiatan utama yang bersifat ramah dan menyenangkan.

- Accessibility and accommodation: selalu terbuka saat diperlukan dan memenuhi semua kebutuhan penggunjung.

- The regulars: memiliki pengunjung tetap yang mendasari karakteristik tempat namun juga menyambut pengunjung baru untuk merasa nyaman.

- A low profile: tanpa pemborosan atau hal yang berlebihan, kesederhanaan yang dapat menerima semua pengunjung dari berbagai latar belakang pengalaman hidup, memiliki kesan rumah bagi pengunjung.

- The mood is playful: menciptakan suasana yang ringan jauh dari adanya konflik atau pun pertentangan yang tidak menyenangkan.

- A home away from home: menyediakan kehangatan seakan-akan merasa bagian dari komunitas, seperti rumah sendiri, di mana pengunjuk mendapati energy positif dari lingkungannya.

\section{Stress}

Berdasarkan penelitian yang dilakukan oleh perusahaan asal Inggris, yaitu Zipjet, Kota Jakarta menempati peringkat 18 dari 150 dalam hasil survei peringkat kota dengan tingkat stres paling tinggi di Asia tahun 2017. "Kegelisahan dan stress telah ditunjukkan berulang kali sebagai faktor kunci yang berkontribusi terhadap kemerosotan kesehatan mental dan kualitas hidup," tulis Zipjet pada hasil penelitiannya. Ada 17 kriteria yang dijadikan acuan, yang mencakup : kepadatan, ruang terbuka hijau, kemacetan, pekerjaan, keamanan sosial, kesehatan jiwa, kesehatan fisik, kesetaraan gender, dll. (Kriteria penilaian survei dalam skala 1-10 yang berarti semakin tinggi angka variablenya maka semakin menunjukan bahwa semakin tinggi juga tingkat stressnya.)

Kriteria-kriteria yang perlu diperhatikan antara lain :

$\checkmark$ Pertama adalah jumlah kepadatan. Untuk poin ini, Jakarta memperoleh skor 9,28 dari maksimal nilai 10 yang berarti mempertegas Ibu kota Indonesia ini sangat padat.

$\checkmark \quad$ Kedua adalah ruang hijau. Untuk poin ini Jakarta memperoleh nilai 9,58 yang berarti ruang terbuka hijau dinilai sangat kurang.

$\checkmark$ Ketiga adalah tingkat kemacetan lalu lintas. Jakarta diberi nilai 9,15 untuk tingkat kemacetan.

$\checkmark \quad$ Keempat adalah tingkat kesehatan jiwa yang menyentuh angka 7,52. Dan yang kelima adalah tingkat kesehatan fisik, yang dimana Jakarta diberi nilai 9,01. Data tersebut menunjukkan bahwa kesehatan jasmani maupun rohani penduduk Jakarta sangat tidak sehat.

Psikolog Klinis Ratih Ibrahim (2017) menyebutkan bahwa, stress merupakan hal lumrah yang bisa terjadi kapan saja dalam hidup manusia. Berdasarkan dari hasil survei diatas, secara umum stress memang dialami oleh seluruh penduduk kota-kota besar di dunia. "Kenapa? 
Karena intensitas kompetisinya juga tinggi. Kurangnya ruang hijau, kemacetan, pergerakan yang sangat dinamis, ruang hidup yang semakin sempit, itu semua aspek yang berpengaruh terhadap level stres seseorang," katanya, dalam Metro Siang, Selasa 7 November 2017. Ratih mengatakan pada dasarnya Jakarta sama dengan wilayah kota-kota besar lainnnya. Merujuk pada tulisan The World is Flat, kata Dia, semakin lama wajah kota besar akan semakin sama. Kesamaan tersebut berkaitan dengan wilayah yang semakin datar, padat, ramai, lingkungan gerak yang semakin sempit juga membuat orang lebih rentan terkena stress.

\section{Stress Management \\ $\checkmark$ Meditasi}

Beberapa pakar beranggapan bahwa meditasi merupakan salah satu cara yang ampuh mengatasi stres. Meditasi akan membantu seseorang memusatkan pikiran dan perasaan agar bisa berkonsentrasi dan relaksasi. Dengan begitu, pernapasan akan menjadi lebih teratur, detak jantung dan tekanan darah akan kembali normal. Kondisi ini tentu dapat menurunkan hormon stress sehingga tubuh menjadi lebih tenang. Menurut hasil penelitian, meditasi selama 15 menit bisa memberikan efek yang sama pada kebugaran tubuh seperti olahraga selama 1 jam.

\section{$\checkmark$ Berolahraga}

Secara ilmiah dapat dijelaskan bahwa dengan berolahraga, akan meningkatkan produksi hormon endorphin yang mampu memberikan efek relaksasi pada pikiran. Selain itu, olahraga juga memobilisasi otot, mempercepat peredaran darah, dan membuka paru-paru untuk mengambil oksigen lebih banyak. Dengan demikian, kondisi tubuh menjadi stabil dan lebih sehat.

$\checkmark$ Relaks

Ketika stress mulai melanda, relaks dan menghirup udara segar merupakan alternatif yang patut dipertimbangkan. Bertahan pada situasi dan posisi yang monoton tidak akan bisa mengatasi stress, justru akan semakin memburuk kondisi. Untuk itu, pergilah keluar ruangan dan hirup udara segar walau sebentar. Sebab, udara segar dapat membantu menenangkan diri sehingga bisa kembali berpikir jernih.

\section{$\checkmark$ Bersosialisasi}

Bertemu dengan teman, keluarga, tetangga untuk berinteraksi dan berbincang merupakan obat penghilang stress terbaik. karena manusia merupakan makhluk sosial yang apabila terisolasi dari lingkungan sosial, yang terjadi adalah mengidap depresi dan kecemasan terkait stress.

\section{METODE}

\section{Behavior Architecture}

Behavior architecture merupakan salah satu metode desain yang mengutamakan perilaku pengguna sebagai faktor utama dalam mempertimbangkan alternatif rancangan. Beberapa ahli berpendapat bahwa tiap individu memiliki kegiatan dengan tujuan masing- masing, yang dimana tujuan tersebut dijadikan sebagai motivasi untuk memenuhi keinginan dan kebutuhannya. Pada metode ini, hal tersebut yang dijadikan analisis utama dalam perancangan.

\section{Everydayness}

Konsep everydayness dipahami dalam menghasilkan sebuah karya arsitektur yang lebih humanis. Karena di konsep inilah manusia sebagai penghuni diutamakan dan aspek sosial, budaya, religi, dan norma-norma yang berlaku di tempat tinggalnya diperhitungkan. Konsep ini menitikberatkan untuk memahami skenario yang berlaku pada konsep dari tempat tersebut, sehingga proyek yang dihasilkan tidak bersifat alien yang pada akhirnya berujung kesia-siaan. Konsep everydayness adalah konsep yang berkaitan dengan intelektual, bahasa dan 
percakapan. Everyday life bersifat 'sangat sekarang', namun tak luput dari masa lalu. Yang ada sekarang adalah kelanjutan dari masa lalu. Jika kita dapat mengetahui masa lalu maka akan sangat membantu dalam merunut ke masa sekarang dan berguna dalam mengambil keputusan desain. Dengan demikian perlu disadari untuk tidak mengabaikan keberadaan dari everyday life. (Lefebvre, 1997). Isu domesticity dan rutinitas yang dilakukan merupakan bagian dari pemahaman konsep everyday. Dalam uraian Berke, penting untuk menyoroti kebutuhan pengguna sehingga program dan konstruksi menjadi terfokus, selain itu aspek sosial, budaya dan aspek manusia lainnya harus masuk dalam pertimbangan. Oleh karena itu, metode partisipasi dalam pengumpulan data merupakan cara yang baik dalam menghasilkan sebuah karya yang dekat dengan penghuni dan lebih humanis.

\section{Pengumpulan data}

Dilakukan survey, mapping, dan wawancara di tapak yang terletak di Jalan Daan Mogot RT 6 RW 4, Jelambar, Grogol Petamburan, Jakarta Barat hingga kawasan di sekitarnya dengan radius kurang lebih hingga $1 \mathrm{~km}$.

\section{DISKUSI DAN HASIL}

\section{Tapak}

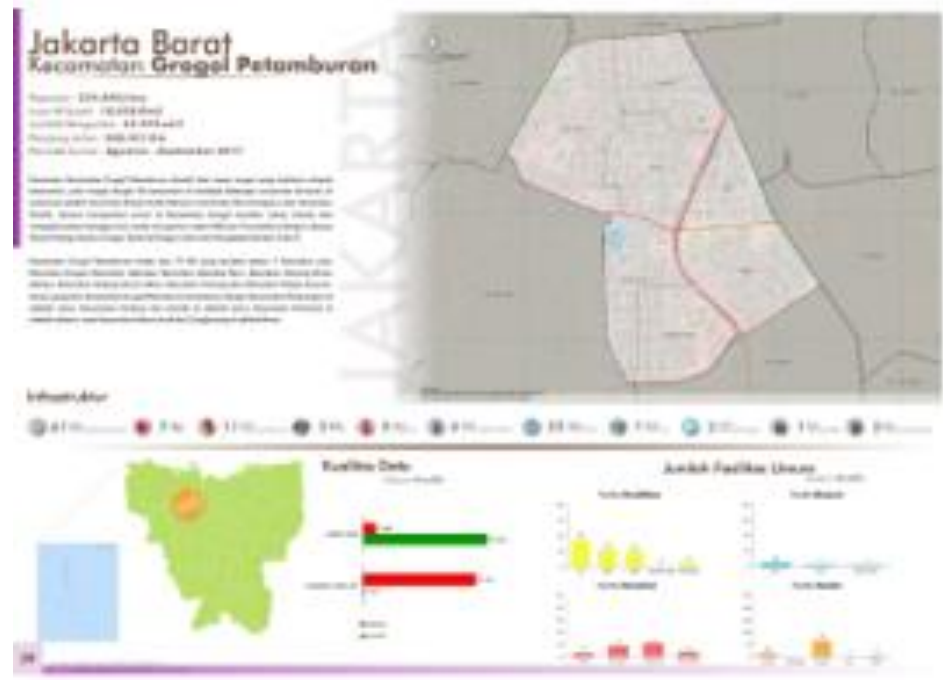

Gambar 1. Peta Jakarta Barat-Grogol Petamburan Sumber: Openatreetmap.id, 2019

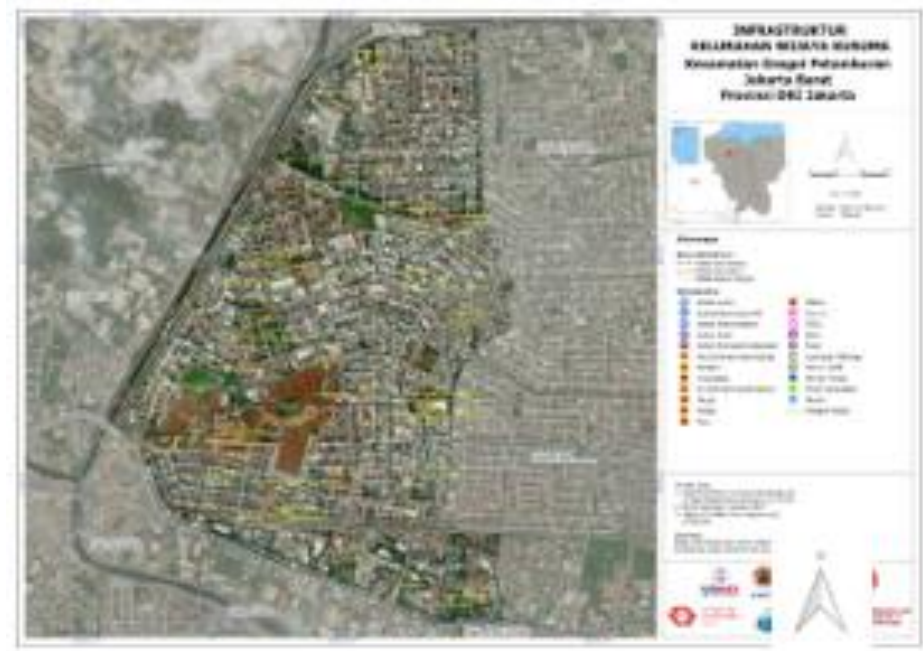

Gambar 1. Peta Infrastruktur Kelurahan Wijaya Kusuma Sumber: Openatreetmap.id, 2019 
Berdasarkan data scoring kawasan Jakarta Barat ditunjuk sebagai kawasan terpilih dengan hasil skor tertinggi dibandingkan dengan kawasan yang lain, berdasarkan parameter pembanding yang ada. Masuk ke lingkup yang lebih kecil, ada 3 kecamatan yang memiliki kemungkinan untuk dijadikan tapak berdasarkan scoring yakni Grogol Petamburan (yang jumlah penduduknya 237.321 jiwa), Palmerah (yang jumlah penduduknya 228.552 jiwa), dan Taman Sari (yang jumlah penduduknya 129.035 jiwa). Karena isu yang diambil merupakan density, dipilihlah kawasan dengan jumlah penduduk terbanyak, yakni Grogol Petamburan. Masuk ke lingkup yang lebih spesifik, dari 7 kelurahan yang ada di Grogol Petamburan, terpilihlah Kawasan Wijaya Kusuma yang memiliki total penduduk 44.841 jiwa.

\section{Analisa Tapak}

Analisa tapak yang mencakup aksesbilitas, zoning kegiatan, zoning pengguna, mapping $3 \mathrm{~A}$ dilakukan dengan survey pada daerah kawasan Grogol Petamburan tepatnya di kelurahan Wijaya Kusuma.

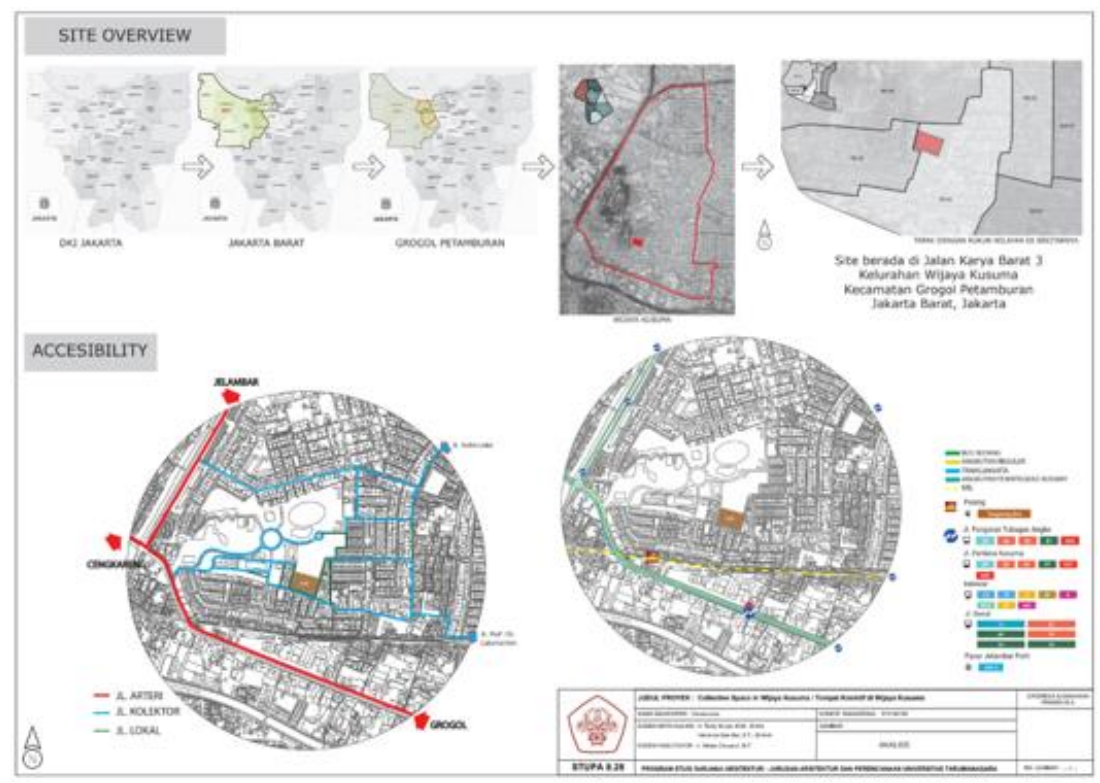

Gambar 3. Site overview and accessibility Sumber: Penulis, 2019

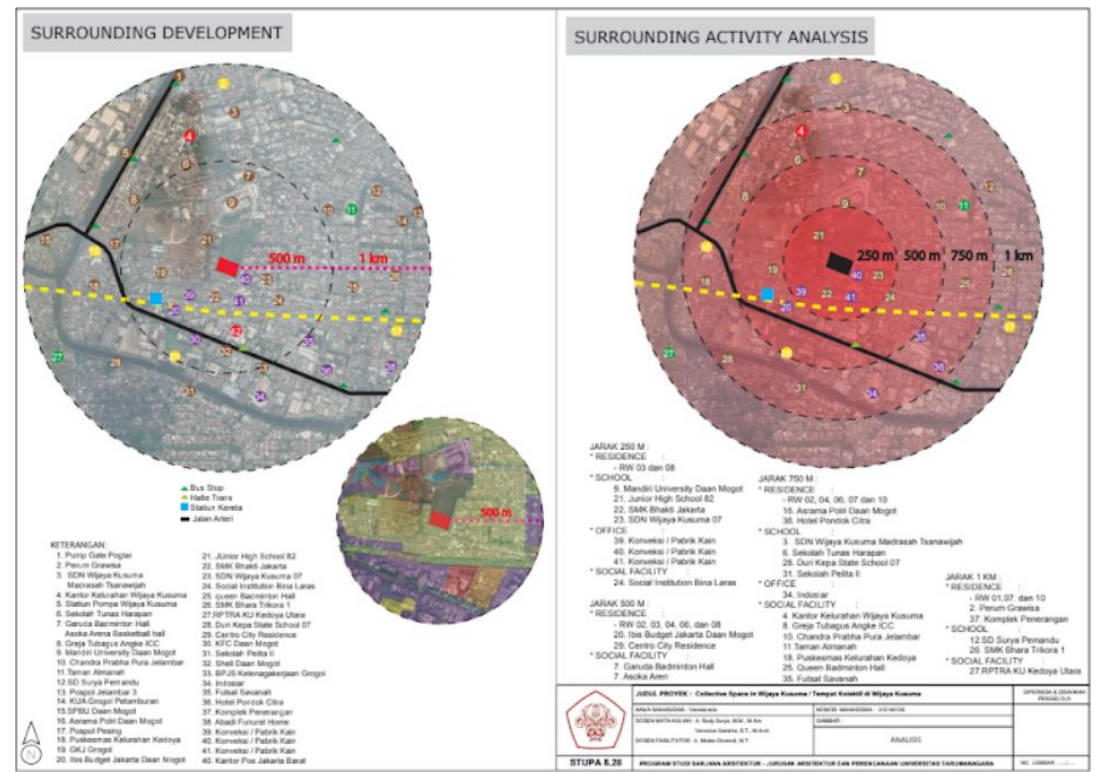

Gambar 4. Surrounding Development dan Activity Analisis

Sumber: Penulis, 2019 


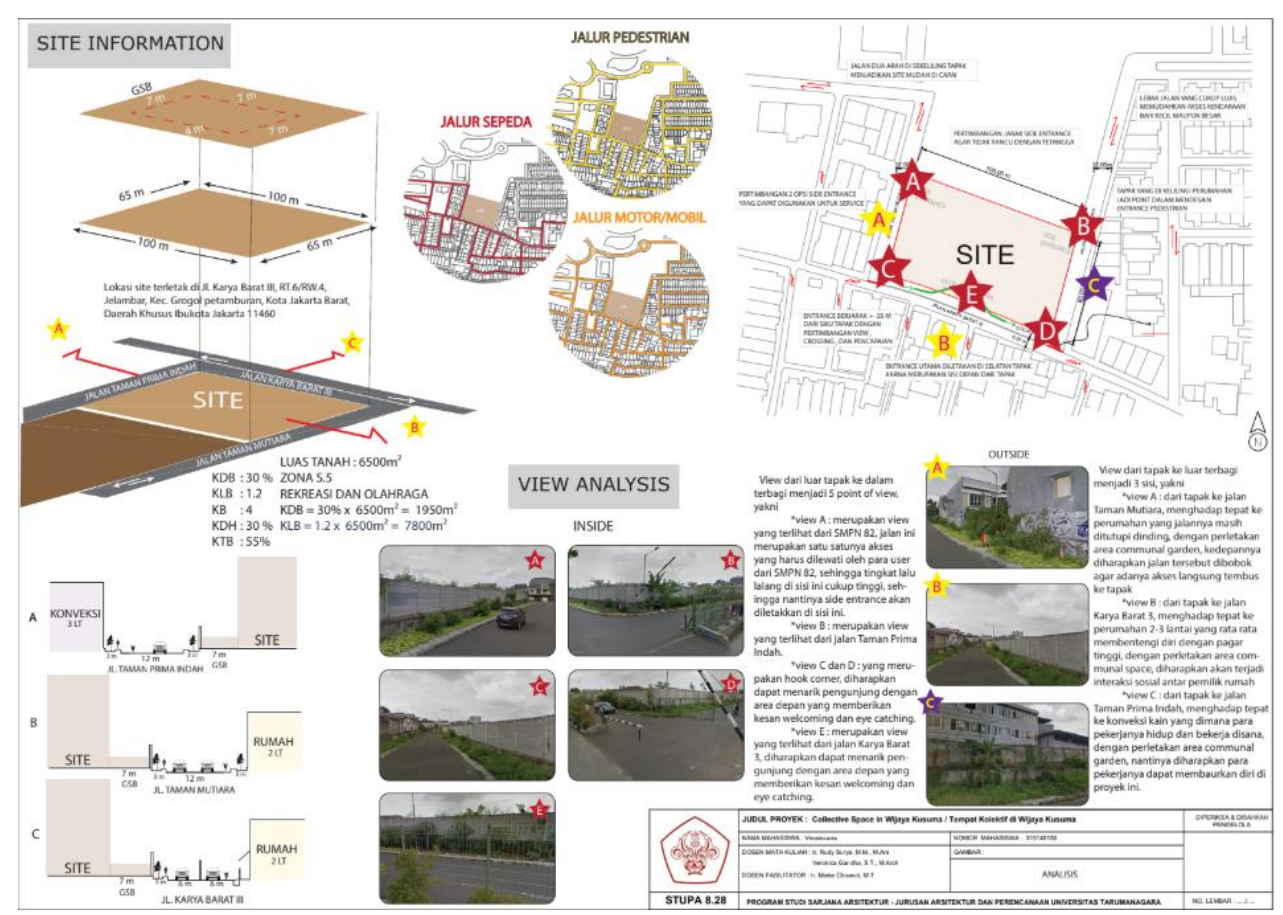

Gambar 5. Site Information dan View Analysis

Sumber: Penulis, 2019

\section{Mapping Akses dan Zonasi}

Untuk Akses pencapaian eksisting, jalan menuju tapak hanya dapat dilalui dengan menempuh jalan lokal dengan lebar jalan $6 \mathrm{~m}$, tapi menurut peta operasional 2030, kedepannya akses jalan dapat ditembus langsung dari jalan arteri (melewati stasiun pesing), dan diperlebarnya jalan lokal menjadi jalan kolektor selebar $12 \mathrm{~m}$. Untuk zonasi sekitar tapak, dikelilingi oleh zona permukiman, zona pendidikan, dan zona perkantoran, yang dimana memenuhi kriteria untuk menjadi third place dikarenakan terletak di antara first place (high density housing) dan second place (education and business centre).

\section{Mapping Permasalahan}

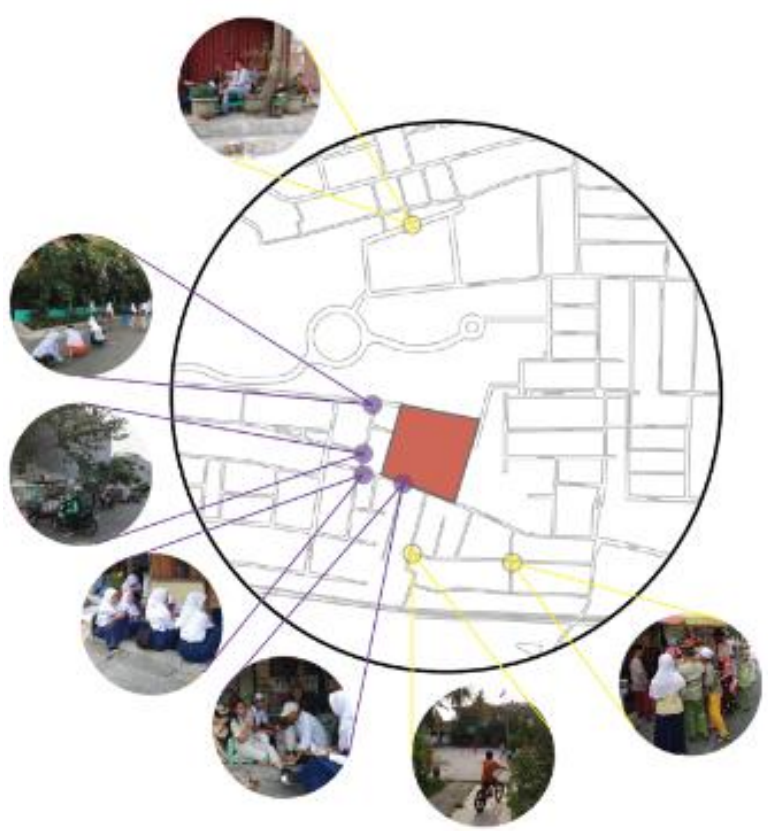

Gambar 6. Mapping Permasalahan Sumber: Penulis, 2019 
Seperti yang dapat dilihat pada mapping disamping, untuk pengguna dari first place, kurangnya wadah untuk mereka berkumpul mengakibatkan mereka duduk ngopi di depan ruko; untuk pengguna anak anak dan remaja, tidak adanya wadah untuk mereka berkumpul bermain bersama membuat mereka mengambil tempat di lapangan sekolah maupun di tengah jalan. Sedangkan untuk pengguna second place, kurangnya wadah untuk mereka berkumpul mengakibatkan mereka berkumpul di warung, dan bahkan didepan rumah warga, para pkl dan ojek pun berjejer di jalan raya, anak-anak sekolah yang gemar melakukan kegiatan ekstrakurikuler pun tidak memiliki wadah untuk menampung kegiatan yang mereka lakukan, sehingga jalan raya depan sekolah pun dijadikan alternatif untuk mereka melakukan kegiatannya.

\section{SWOT}

Tabel 1. SWOT

\begin{tabular}{|c|c|}
\hline & TAPAK \\
\hline STRENGHT & $\begin{array}{l}\text { Terletak 500m dari Stasiun Pesing. Terletak 500m dari Halte Busway Pesing. } \\
\text { Dalam radius 500m terdapat Sekolah Tunas Harapan, Kantor Kelurahan, Sekolah YP- BDN, } \\
\text { Hotel IBIS Budget, Panti Sosial Bina Laras, PT.Triinti Internasional, SDN } 07 \text { Pagi, Rusun Polri } \\
\text { Pesing, Centro City Residence, Gedung Indosiar } \\
\text { Dalam radius } 1 \mathrm{~km} \text { terdapat PMI Jakarta Barat, Perumahan Grawisa, Komplek Duta Square, } \\
\text { Perum Griya Bukit Jaya } \\
\text { Banyaknya transportasi umum yang lewat sehingga memudahkan akses pengunjung } \\
\text { Pedestrian tertata dengan rapi dan baik }\end{array}$ \\
\hline WEAKNESS & Terletak di jalan Kolektor Karya Barat III Terletak di kawasan macet \\
\hline OPPORTUNITY & $\begin{array}{l}\text { Dikelilingi permukiman dan perkantoran yang terdiri dari berbagai macam komunitas, } \\
\text { yang memiliki anggota dari berbagai macam umur, gender, kalangan, dsb } \\
\text { Adanya kebutuhan akan tempat untuk bertukar pikiran, menjalin hubungan antar individu, } \\
\text { dan menikmati waktu luang selain di tempat tinggal maupun di tempat kerja Kawasan } \\
\text { sekitaran tapak terdiri dari area residential, perkantoran, dan institusi pendidikan, } \\
\text { sehingga memungkinkan dibuatnya hybrid programming di tapak } \\
\text { Potensi untuk membuat community / activity center yang dapat merangkul berbagai } \\
\text { jenis kalangan individu di kawasan tapak agar dapat bersosialisasi dan berekreasi untuk } \\
\text { mencapai tujuan hidup humanis, terbuka, dinamis, dan produktif }\end{array}$ \\
\hline THREAT & $\begin{array}{l}\text { Belum masuk kategori } 24 \text { hour city, jadi kegiatan sampai malam perlu diperhatikan } \\
\text { keamanannya }\end{array}$ \\
\hline
\end{tabular}

Sumber: Penulis, 2019

Ide

Setelah dilakukannya pendekatan behavior architecture dan everydayness, yang dimana manusia sebagai penghuni diutamakan dan aspek sosial, budaya, religi, dan norma-norma yang berlaku di tempat tinggalnya diperhitungkan, terlihat bahwa pengguna dari lingkup first place membutuhkan wadah untuk kegiatan sehari-harinya sebagai berikut :

Tabel 2.Waktu Pengguna First Place

\begin{tabular}{|c|c|c|c|c|c|}
\hline & & \multicolumn{4}{|c|}{ Waktu Penggunaan } \\
\hline & & Pagi & Siang & Sore & Malam \\
\hline \multirow{4}{*}{ Pengguna } & Anak-anak & & & Bermain & \\
\hline & Remaja & & & Bermain & Berinteraksi \\
\hline & Dewasa & Olahraga & & Berinteraksi & Berinteraksi \\
\hline & Lansia & Olahraga & & Berinteraksi & \\
\hline
\end{tabular}

Sumber: Penulis, 2019 
Disisi lain, pengguna dari lingkup second place membutuhkan wadah untuk kegiatan sehariharinya sebagai berikut :

Tabel 3.Waktu Pengguna Second Place

\begin{tabular}{|c|c|c|c|c|c|}
\hline & \multicolumn{4}{|c|}{ Waktu Penggunaan } \\
\hline & & Pagi & Siang & Sore & Malam \\
\hline \multirow{3}{*}{ Pengguna } & Anak-anak & & & Bermain & \\
\hline & Remaja & & Berinteraksi & Berinteraksi & \\
\hline & Dewasa & & Berinteraksi & Berinteraksi & Berinteraksi \\
\hline
\end{tabular}

Sumber : Penulis, 2019

\section{Program}

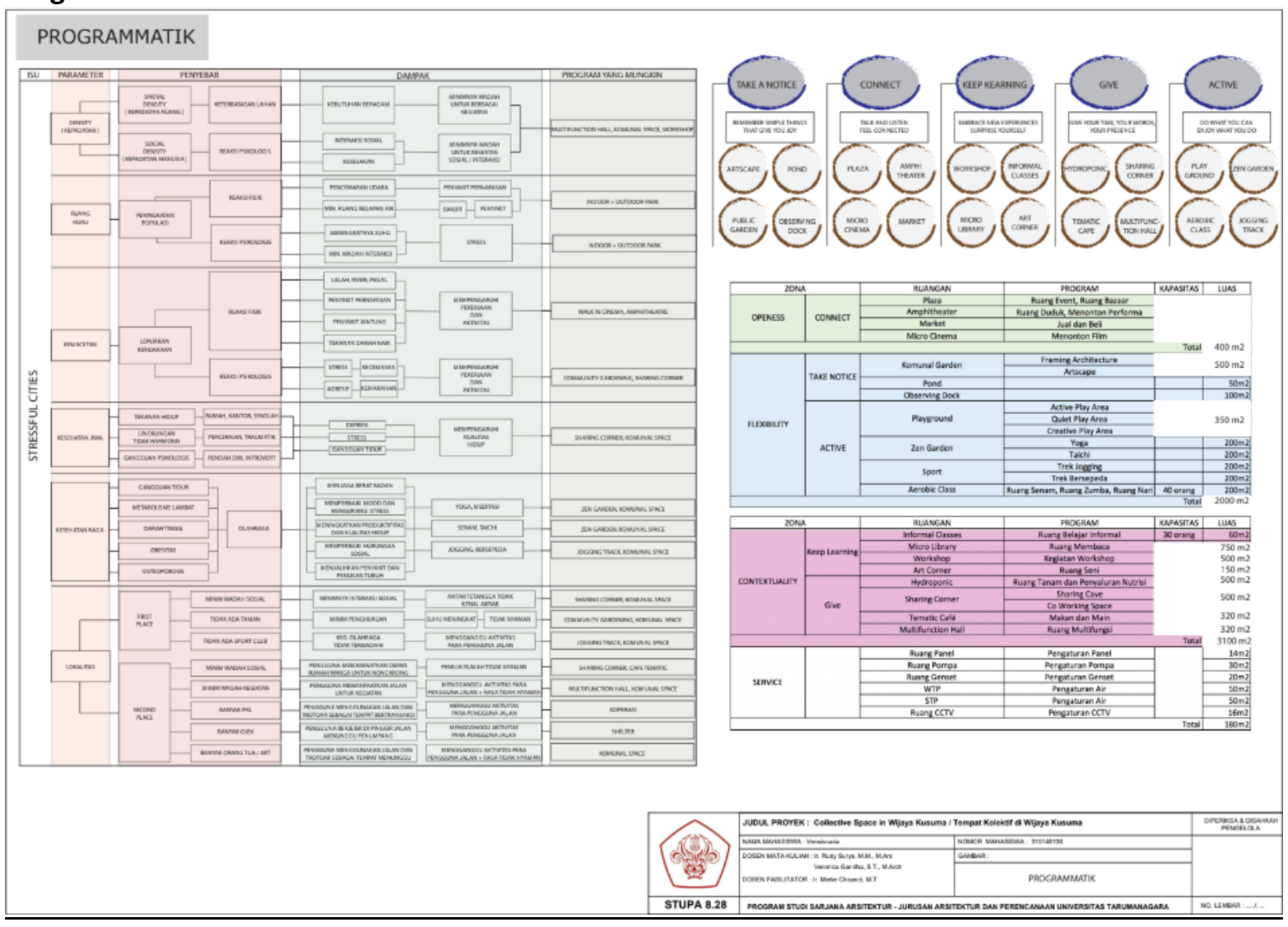

Gambar 6. Programmatik

Sumber: Penulis, 2019 


\section{Gambar Kerja}

Design Scheme

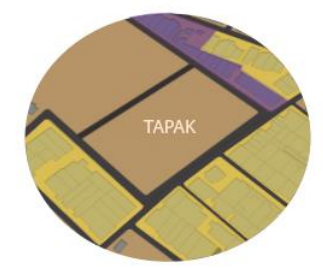

Tapak dikelilingi oleh jalan, berada di antara kawasan permukiman, konveksi, dan sekolah.

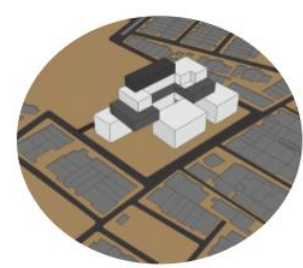

Massing lantai 2 keatas dibuat maju mundur mengikuti kebutuhan ruang dengan pembagian yang sistematis dan modular, hal ini secara tidak langsung memunculkan bentuk

dasar Lego yakni cubical.

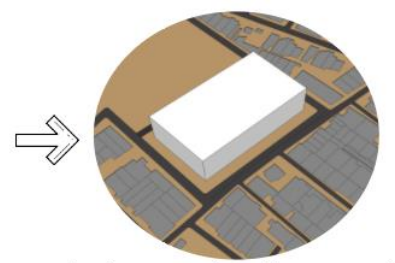

Awalnya massing dibuat semaksimal mungkin dengan mengikuti peraturan yang sudah ditetapkan, mencakup KDB, KLB, KB KDH, dan GSB.

Gambar 7. Design Scheme

Sumber: Penulis, 2019

Denah

Berlokasi di jalan Daan Mogot, RT.6/RW.4, Jelambar, Kec. Grogol petamburan, Kota Jakarta Barat, Daerah Khusus Ibukota Jakarta 11460. Site memiliki luas tapak total sekitar $21.220 \mathrm{~m} 2$ akan tetapi yang dirancang hanya seluas $6.500 \mathrm{~m} 2$. Berada di zona peruntukan $\mathrm{S} .5$ Rekreasi Olahraga. Site memiliki peraturan KDB sebesar 30\%, KLB 1.2, KB 4, KDH 30\%, KTB 55.

Dalam perancangan denah, lantai basement hanya digunakan untuk servis, sedangkan lantai dasar dibuat sepublic dan seterbuka mungkin, dengan program yang lebih menjalin kebersamaan, seperti : taman, amphiteater, playground, workshop, hydroponic. Sedangkan lantai 2 dan lantai 3 berisi program yang lebih edukatif, seperti : perpustakaan, co-work space, studio. Khusus untuk lantai 4 merupakan zona untuk kantor pengelola.

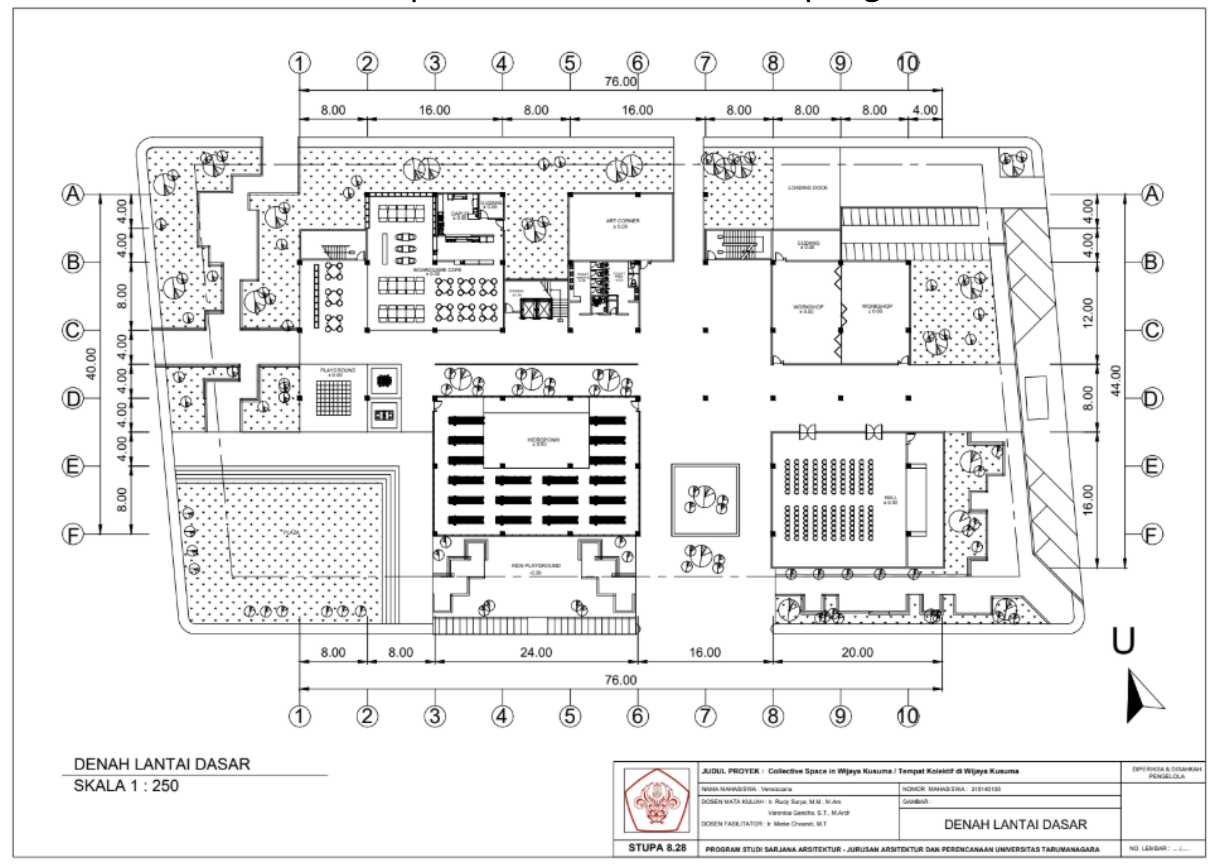

Gambar 8. Denah Lantai Dasar

Sumber: Penulis, 2019 

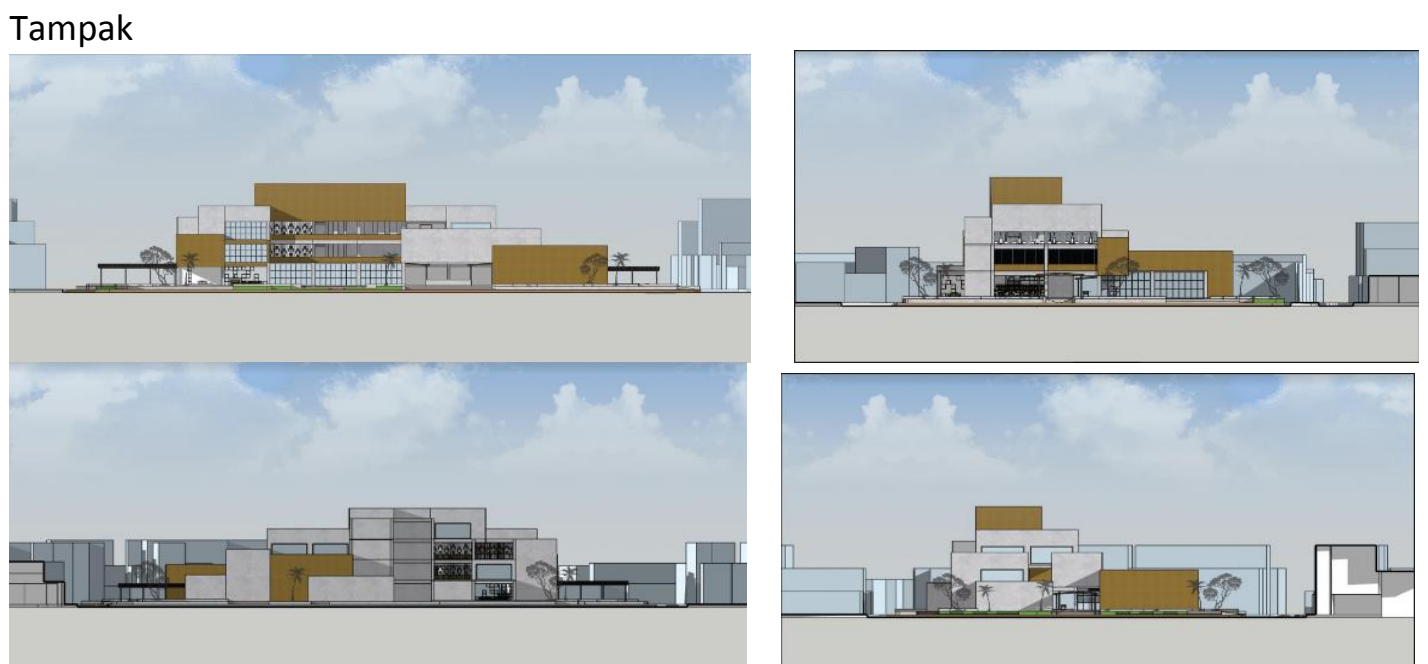

Gambar 9. Tampak

Sumber: Penulis, 2019

Tampak memang sengaja didesain sedemikian rupa agar menonjolkan ciri khas lego yang merupakan kotak kotak simetris dan beraturan, dilihat dari sisi utara, barat, timur, maupun selatan, proyek terlihat seperti kubus yang tersusun yang saling mengikat. Untuk material pelapis bangunan, masih menggunakan material yang sama, akan tetapi dibedakan warnanya, agar bangunan terlihat memiliki warna yang playful.

\section{Potongan}

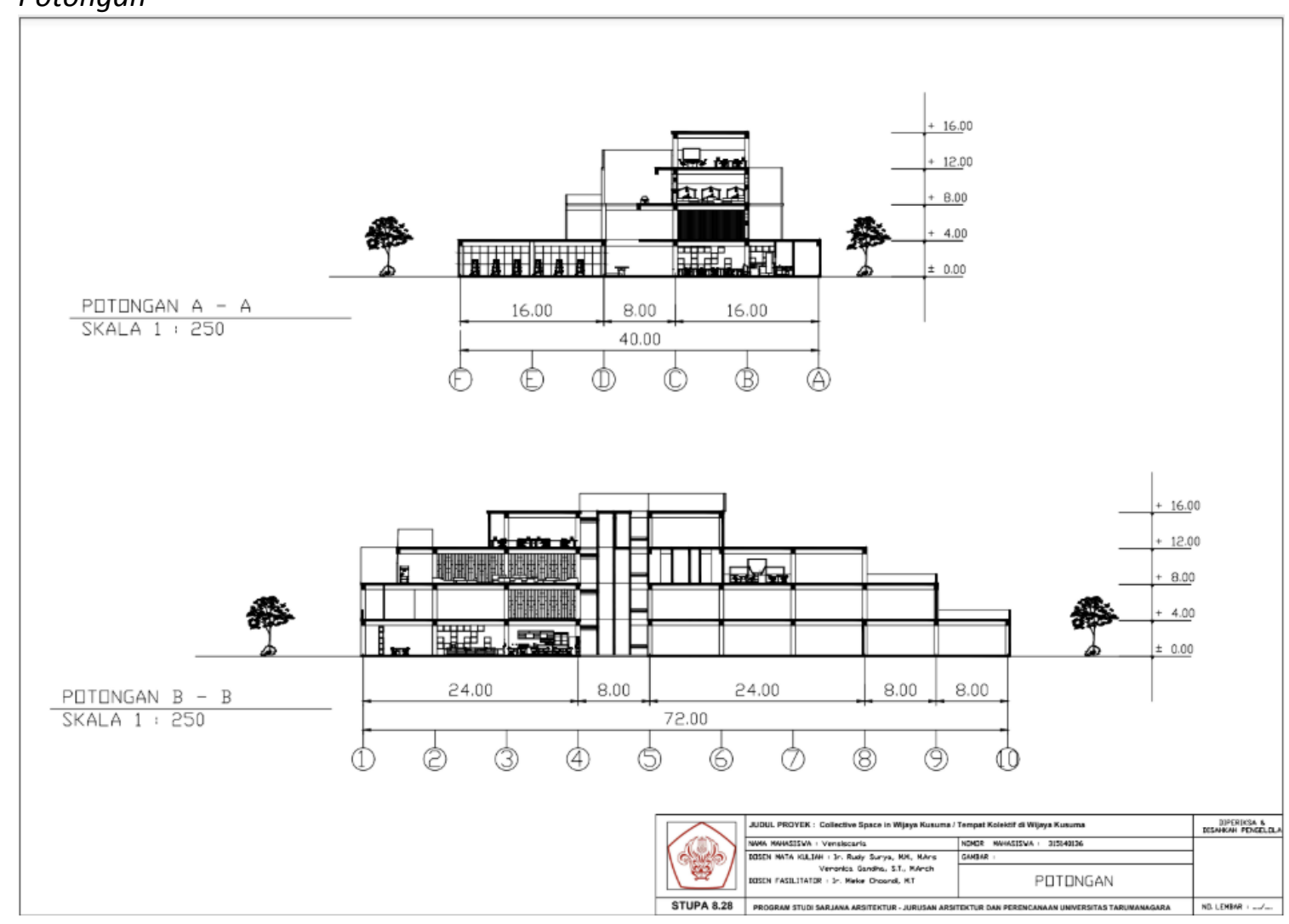

Gambar 10. Potongan

Sumber: Penulis, 2019 


\section{KESIMPULAN DAN SARAN}

Third place berperan sebagai living room of society, dimana program yang disediakan haruslah merupakan ruang untuk aktivitas yang bersifat netral, dimana setiap kalangan dapat bertukar pikiran, menikmati waktu yang menyenangkan, serta membangun hubungan dengan nyaman tanpa diskriminasi. Third place juga berperan sebagai ruang antara untuk masyarakatnya melarikan diri dari rutinitas first place dan second place yang berjalan beriringan dengan menjawab isu sosial di kawasan lingkungan itu sendiri. Stressful cities berkaitan erat dengan kepadatan populasi penduduk Jakarta yang dimana berbanding lurus dengan keterbatasan lahan yang ada. Disaat kebutuhan dan kegiatan yang harus dipenuhi terus meningkat, timbul ketidakseimbangan antara kebutuhan dengan wadah yang tersedia, dengan kata lain, kepadatan penduduk yang tinggi tidak diimbangi dengan fasilitas yang mendukung untuk saling berinteraksi. Untuk itu diperlukan fasilitas di mana masyarakat dapat melakukan kegiatan bersama di luar kegiatan bermukim dan bekerja. Dengan pendekatan behavior architecture dan everydayness serta metode hybrid programming, third place yang diciptakan akan mengikuti aspek sosial, budaya, religi, dan norma-norma yang berlaku di kawasan lingkungannya. Sehingga program yang dihasilkan tidak bersifat alien yang pada akhirnya berujung pada suatu kesia-siaan.

\section{REFERENSI}

Larice, M., \& Macdonald, E. (2007). The urban design reader, second edition. London: Routledge.

Marcella, J. (2004). Arsitektur \& perilaku manusia. Grasindo.

McLaren, D., \& Agyeman, J. (2015). Sharing cities: a case for truly smart and sustainable cities. MIT press.

Oldenburg, R. (1999). The great good place: Cafes, coffee shops, bookstores, bars, hair salons, and other hangouts at the heart of a community. New York: Marlowe \& Co.

Tschumi, B. (1996). Architecture and disjunction. MIT press.

https://jakbarkota.bps.go.id/publication

https://republika.co.id/berita/nasional/umum/16/08/30/ocpa9m382-ini-penyebab-orangkota-sering-dicap-individualis

https://thriveglobal.com/stories/simple-yet-efficient-stress-management-tips

https://www.medcom.id/rona/kesehatan/ybDMMMjk-jakarta-dinobatkan-salah-satu-kotadengan-tingkat-stres-tinggi-psikolog-itu-lumrah 